\title{
JUDÔ E ESPORTE DOS MAIS JOVENS: OS PAIS NO CENÁRIO COMPETITIVO.
}

Fabiano Filier Cazetto

Pablo Christiano Lollo

Roberto Rodrigues Paes

José Vitor Vieira Salgado

\section{Resumo}

A competição de Judô dos mais jovens foi o foco desde estudo, procurou-se traçar um quadro que descreve-se a imagem construída simbolicamente pelos pais de judocas das categorias mirim, infantil, infanto-juvenil. Inicialmente utilizou-se uma entrevista aberta para auxiliar na construção de um instrumento fechado baseado em escala de atitudes. Os pais são importantes "personagens" no ambiente da competição infantil, para eles competir é algo necessário e natural. O Judô é visto como sinônimo de esporte e com valores positivos, porém aceita-se que ele também seja um momento de seleção em que os pais tenham uma influência negativa sobre os filhos. Os pais têm papel fundamental na construção do cenário competitivo, sua influência se da na relação com filhos, professores e dirigentes. Neste sentido destaca-se a importância de que o professor assuma seu papel profissional para um bom aproveitamento educacional deste ambiente auxiliando os mais diversos "personagens".

\section{Palavras-Chave}

Judô; Competição; Infância.

\section{JUDO AND YOUNGEST ONES SPORT: PARENTS IN COMPETITION.}

Fabiano Filier Cazetto

Pablo Christiano Lollo

Roberto Rodrigues Paes

José Vitor Vieira Salgado

\begin{abstract}
This study is about de judo competition of the youngest. It builds a description of the symbolical image constructed by the parents. The age of their children is between 6 and 12 years old. Initially has been build a interview in which has bee based the Likert scale survey. The parents are very important in the childhood competition, they think the competition as necessary and natural. Judo is seen as a sport synonymous that teaches good values, however is accept that the some parents have bad influence over the children in competition. This phase is also seen as a selection stage. The parents are extremely important in the competition construction, they influence children, coaches, and administrators. This way is important that the coaches/professors assist not just the students, but also parents.
\end{abstract}

\section{Key-Words}

Judo; Competition; Childwood. 


\section{INTRODUÇ̃̃O}

$\mathrm{O}$ esporte, tal como o conhecemos atualmente, é fruto das transformações ocorridas na Europa devido à Revolução Industrial dos séculos XVIII e XIX, ele vêem ocupando cada vez mais espaço na vida das pessoas especialmente crianças e jovens. (DE ROSE, 2002).

O fenômeno esporte é uma representação simbólica da vida, de natureza educacional, podendo mover no praticante modificações tanto na compreensão de valores, como de costumes e modo de comportamento, interferindo no desenvolvimento individual, aproximando pessoas que têm, neste fenômeno, um meio para estabelecer e manter um melhor relacionamento social. (PAES, 2005).

Ainda que haja inúmeras críticas ao fenômeno esportivo, que este possa ser considerado um instrumento reacionário da classe dominante ou um aparelho ideológico do Estado, servindo de compensação na sociedade capitalista (PRONI, 2002), o esporte é o que fazemos dele, parafraseando Damatta (1982) cada sociedade tem o Judô que merece, o autor coloca que o esporte faz parte da sociedade tanto quanto a sociedade faz parte do esporte, suas relações são como duas faces da mesma moeda e não como o telhado e o alicerce de uma casa.

No Judô temos a divisão por CLASSES, distinguidas pelo ano de nascimento do indivíduo (FEDERAÇÃO PAULISTA DE JUDÔ, 2005), elegemos aqui como foco principal às classes MIRIM, INFANTIL, INFANTO-JUVENIL, que envolvem idades entre seis e treze anos de idade. Elegemos essas classes para estudo por entendermos que os iniciantes, sobretudo os mais jovens devem ter um tratamento coerente e diferenciado dos demais praticantes, faz-se necessário uma produção acadêmica e ações políticas que contemplem essas populações.

As abordagens biológicas, por exemplo, Malina e Bouchard (2002), Matsudo (2002) e Forjaz (2002) também defendem que a atividade física, que neste caso específico se manifestará na modalidade esportiva do Judô, se trabalhada coerentemente trarão benefícios aos mais jovens. Cabe assim entender que os mais jovens têm necessidades e potencialidades diferenciadas dos adultos, no entanto, os "personagens" do "cenário" esportivos nem sempre tem isso em mente. Simões, Böhme, Lucato afirma sobre a imagem que os pais podem fazer dos filhos que praticam esporte:

[..] De fato, pode existir o risco das crianças, funcionalmente falando, serem consideradas num ponto como "atleta em miniatura". Portanto, a maneira como pais e mães agem com as crianças parece significativa no estabelecimento de um conjunto de linhas bem definidas de participação na vida esportiva das crianças. [...] (SIMÕES; BÖHME; LUCATO,1999, p.41) 
Estes autores defendem ainda que o esporte infanto-juvenil seja um modelo social que faz parte da formação do ser humano na infância e adolescência, sendo organizado em função de valores sócioculturais. Estabelecem-se assim, vínculos afetivos e ações que envolvem as crianças e os adultos no que estes autores chamaram de "ritual" entre pais e filhos, esta influência poderia ser decisiva na formação esportiva em idades escolares.

O que seria então o Esporte da/na infância? Seria a aplicação do modelo adulto? A preparação para o modelo adulto? Seria um meio de seleção para os futuros atletas? Ou seria algo que pudesse ser prazeroso a criança? Que poderia contribuir com seu presente e seu futuro? Damatta (1982) e Proni (2002) estudam o esporte como elementos da cultura, por tanto, elementos construídos historicamente e assim mutáveis. Podemos caracterizar o Esporte e o Judô como elementos inter-relacionados da cultura corporal que mantém entre si relações complexas, são assim construídos historicamente na vida em sociedade através de nossas ações e do significado que damos a elas. O que temos feito do Judô?

Matsudo (2002) coloca sobre os riscos das atividades físicas para os mais jovens:

[...] Qualquer eventual risco aqui mencionado é menor que as conseqüências de uma infância ou adolescência perdida em frente a aparelhos de televisão, vídeo, computadores e outros comportamentos sedentários, que levam a sociedade a alcançar níveis terríveis de doenças crônico-degenerativas, como diabete, hipertensão, obesidade, hipercolesterolemia, osteoporose, entre outras. [...] (p. 123).

Reforçando essa idéia o autor conclui o capitulo:

[...] As evidências epidemiológicas que consideram a relação custo (risco/benefício permitem concluir que crianças e adolescentes, como preconiza o Programa Agita São Paulo, deveriam acumular pelo menos 30 minutos de atividade física diária de intensidade moderada na maioria dos dias da semana (cinco dias), e se possível todos, de forma contínua e acumulada. E recomendável também que se envolvam em atividades vigorosas, durante 20 minutos, duas ou três vezes por semana [...] (p. 136).

Forjaz (2002) aponta que as funções orgânicas vão se modificando ao longo da vida, dando destaque às ocorridas na adolescência. Assim as adaptações crônicas e agudas em decorrência da atividade física devem ser conhecidas para cada fase do desenvolvimento para que possamos trabalhar programas coerentes com nossos alunos e atletas.

Malina e Bouchard (2002) colocam que o crescimento e o amadurecimento são normalmente influenciados positivamente pela atividade física, mas que este é apenas um dentre diversos fatores. Outro fator importante citado pelos autores é a questão da seleção ou adaptação, ou seja, quando fazemos 
as pesquisas que indicam uma determinada característica física esta é decorrente de adaptação devido à atividade ou de seleção de indivíduos que tem determinada característica.

Ao pensar nas questões de crescimento em estatura Forjaz (2002) colabora para essas afirmações na medida em que diversos autores aceitam que a atividade física é essencial para o crescimento normal, sendo que outros autores ainda defendem que ela pode promover o crescimento aumentado, sendo que está pode ser resultado de seleção. Malina e Bouchard (2002) citam que a atividade física regular não tem nenhum efeito aparente sobre o crescimento em estatura, e que dados que sugiram o contrário são resultados de seleção dos indivíduos para as modalidades. O autor coloca ainda que o adiantamento da maturação pode ser um fator de seleção para as modalidades, sendo que os meninos que amadurecem mais cedo são beneficiados devidos às mudanças física em estatura, composição corporal, força, entre outros, enquanto as meninas normalmente são prejudicadas pelas mudanças decorrentes da maturação, sendo assim aquelas que demoram mais para amadurecer levariam vantagem. Este dado mostra que certas modalidades às quais são atribuídas alterações biológicas muitas vezes são fruto de simples seleção.

[...] a atividade física excessiva pode prejudicar o crescimento estatural, [...], principalmente durante a aceleração do crescimento na puberdade, apresentam ossos frágeis e mais propensos a lesão por sobrecarga (FORJAZ, 2002, p.100)

Forjaz (2002) sugere que se têm atribuído as grandes sobrecargas do treinamento em ginastas como um fator possível para as menores médias de estatura, no entanto a seleção é apontada como fator determinante. Lollo, Cazetto e Montagner (2004) apontam indícios de que práticas pensadas para as idades adultas se tornem inadequadas para eventos crianças ao estudar questões competitivas e aspectos nutricionais. Assim poderíamos inferir que possivelmente métodos e intensidade de treinamento da fase adulta poderiam influenciar o treinamento dos mais jovens, sendo assim essas sobrecargas poderiam ser inadequadas.

Malina e Bouchard (2002) afirmam que muitos jovens abandonam o esporte na medida em que o nível de competição torna-se mais difícil e necessária maior habilidade.

Há muito tempo o judô vem se tornando um esporte competitivo em todas as faixas etárias, principalmente na categoria infantil devido à criação, na antiga gestão da $\mathrm{CBJ}$, dos campeonatos brasileiros de 9/10 11/12 e 13/14 anos. Antes só existiam campeonatos brasileiros para atletas acima de 15 anos. Com o surgimento dos mesmos, as disputas infantis deixaram de ser eventos educativos e descontraídos e começaram a valorizar somente a importância de ser sempre o campeão. (LAPA, 2002). 
$\overline{\text { Competir, ganhar, vencer a qualquer custo, reproduziria exatamente tudo aquilo que os pais querem dos }}$ filhos como "atletas", pois a vida esportiva das crianças, em tudo se associa às influências do ganhar, vencer a qualquer custo, de tal forma que os elementos culturais, sociais e psicológicos envolvidos com formação educacional e esportiva das crianças, só poderiam ser compreendidas através de comportamentos adotados pelas instituições educacionais, das quais elas pertencem. (SIMÕES; BÖHME; LUCATO,1999).

Entendendo que o Esporte é um fenômeno cultural socialmente construído e que os pais têm um papel fundamental nesse contexto o objetivo desse estudo é traçar a imagem dos pais sobre os elementos fundamentais que constroem esse "cenário". 


\section{MATERIAIS E MÉTODOS}

Foi usado um modelo de questionário auto-aplicável e auto-validado extraído e adaptado de Ritz (2000):

\section{DEFINIÇÕES:}

Dimensão - aspecto ou fator considerado importante para uma determinada análise que, no caso, é aquele utilizado para se avaliar a percepção do fenômeno competitivo pelos pais.

Asserção - Afirmação feita sobre determinada dimensão, podendo ser positiva ou negativa.

Instrumento - Meio utilizado para coleta de dados sobre o assunto pesquisado, envolvendo pagina de rosto, onde são dadas as instruções para o respondente; corpo, no qual pulverizam-se as varias asserções envolvendo as dimensões pesquisadas com escala possível de respostas.

Universo de respostas - são as possíveis respostas que o respondente pode escolher. Neste caso são quatro: Concordo Plenamente (CP), Inclinado a Concordar (IC), Inclinado a Discordar (ID) e Discordo Plenamente (DP). Deliberadamente excluímos a opção indiferente da escala, conduzindo um posicionamento positivo, ou negativo frente à asserção, evitando assim a tendência centrante.

Média das Asserções: Calcula-se a média das asserções, somando-se as pontuações obtidas em cada asserção validada e dividindo pelo total de respondentes.

Média das Dimensões: A media das dimensões é a média das médias das asserções validadas que compõem a dimensão.

Os gráficos aqui apresentados nos mostram as médias atitudinais distribuídas por intervalos. Como as pontuações das asserções, neste caso, podem assumir valores de 1 a 4, dividimos o gráfico em 3 áreas, que passaremos a chamar de zonas. Com duas zonas de pontuações próximas dos extremos e uma zona de pontuação intermediária, desta maneira temos:

\section{INTERVALO DAS MÉDIAS}

1,00-1,99 e 3,00-4,00 Zonas Conclusiva

2,00-2,99 Zona Inconclusiva 


\section{APLICAÇÃO DO MÉTODO}

Foi desenvolvido um instrumento fechado de pesquisa do tipo escala atitudinal (LIKERT, 1967), considerando as dimensões relevantes para avaliar a percepção do fenômeno competitivo pelos pais, que foi aplicado em uma amostra da população alvo.

Para cada dimensão, foram feitas três ou mais asserções visando varrer o continuo compreendido por dimensão. Inicialmente foi aplicado em uma amostra menor uma entrevista aberta para auxiliar na construção das dimensões.

\section{VALIDAÇÃO DO INSTRUMENTO}

O instrumento quantitativo utilizado foi analisado quanto à validade de conteúdo e de asserção.

Validade de Conteúdo: Uma proposta inicial do instrumento foi construída, levando em conta entrevistas feitas com três pais. Adicionou-se também colocações feitas por professores, árbitros e dirigentes através de perguntas abertas coletadas por questionário áudio-grafado estruturado. Em seguida se realizou um piloto, agora com o instrumento quantitativo para que fossem realizados os últimos ajustes no instrumento no sentido de esclarecer se as asserções eram: necessárias, concretas, dúbias, específica, mal compreendidas, possuíam fraseologia difícil e adequada aos respondentes.

Validade da Asserção: Esta análise visa depurar o instrumento de asserções óbvias ou que não oferecem possibilidade de se varrer toda a gama de possibilidades de respostas oferecida pela escala adotada para o instrumento. Primeiramente procedemos à análise de um pequeno grupo piloto selecionado por acessibilidade, para termos um entendimento mais claro sobre o conteúdo do instrumento.

\section{DESCRIÇÃO DA AMOSTRA}

A amostra foi constituída pelos pais que concordaram em participar da pesquisa escolhidos aleatoriamente por acessibilidade no Campeonato Regional da $15^{\mathrm{a}}$ Delegacia de Judô juntamente com a Prefeitura Municipal de Valinhos (Estado de São Paulo) no dia 15 de maio de 2005. O grupo de pesquisadores pediu a colaboração da organização e foi prontamente atendido sendo a pesquisa anunciada pelo sistema de som do campeonato.

O critério para exclusão dos questionários dos resultados por nós descritos foi obter mais de $10 \%$ de questões não respondidas ou inválidas (RITZ, 2000). Todos os questionários satisfizeram o critério adotado. Para serem entrevistados os pais eram indagados se tinham filhos que praticassem Judô que Conexões: revista da Faculdade de Educação Física da UNICAMP, Campinas, v. 8, n. 1, p. 164-181, jan./abr. 2010. 
estivessem com idade entre seis e treze anos (categorias Mirim, Infantil, Infanto-Juvenil, e Pré-Juvenil). Foram entrevistados 33 pais, o plano amostral foi definido por acessibilidade. Um questionário foi eliminado por não satisfazer o critério de seleção adotado.

Os resultados estão descritos em média (desvio padrão), a média de idade dos entrevistados foi de 40,16 $(8,8)$ anos, sendo que as idades variaram entre 29 e 49 anos.

\section{RESULTADOS E DISCUSSÃO}

\section{Como os Pais Vêem a Competição}

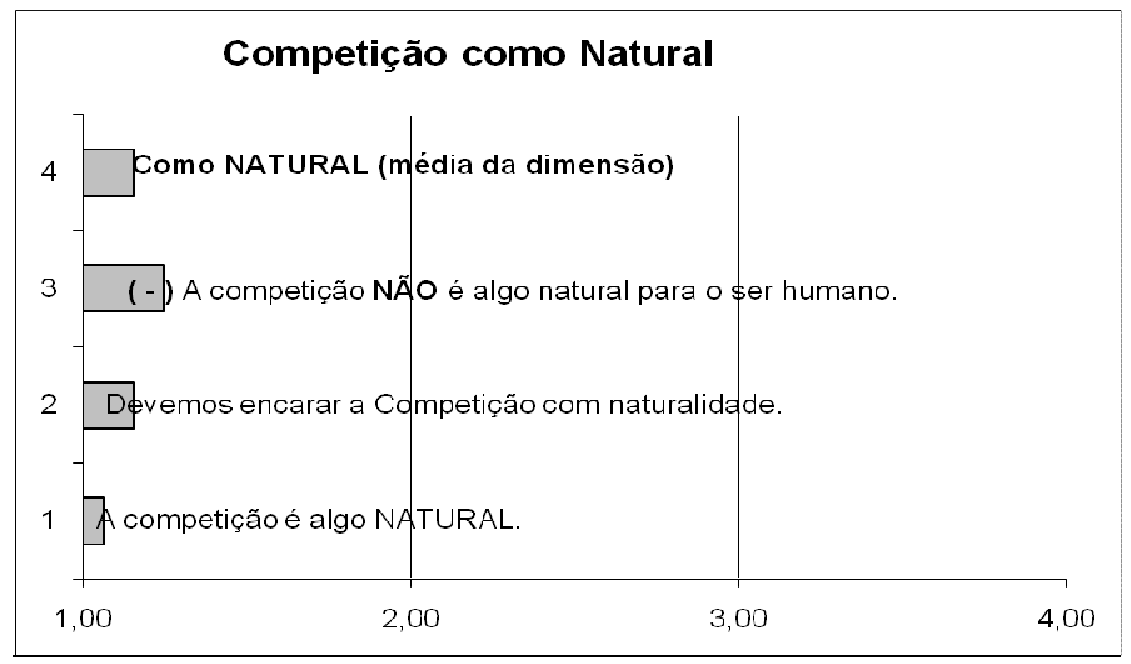

Gráfico 2 - Competição como natural

O resultado ilustrado no gráfico demonstra nitidamente que as respostam ficaram na zona conclusiva positiva $(1,16)$, ou seja, concordam com as asserções que afirma a Competição como algo natural. 


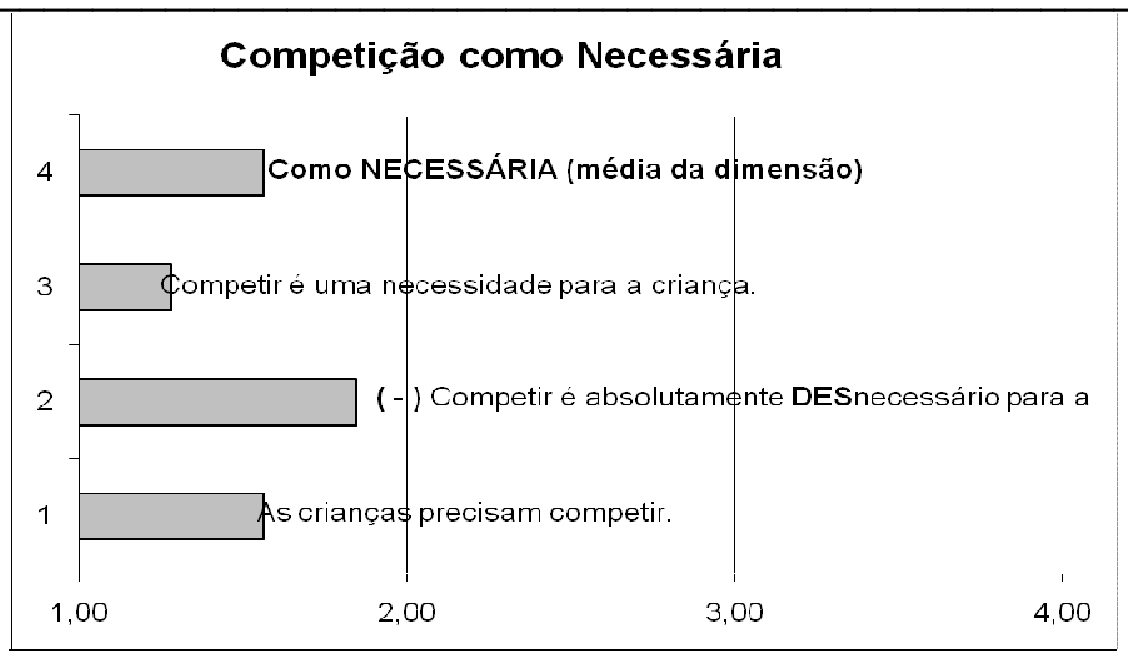

Gráfico 3 - Competição como necessária

No gráfico 3 percebemos a competição como algo necessário também fíca na Zona conclusiva. Observando o valor médio das asserções dessa dimensão $(1,56)$ percebemos claramente que os pais julgam a competição necessária.

A média das duas asserções também é conclusiva $(1,36)$. Estas duas asserções foram agrupadas por conterem idéias do imaginário popular refletidas nas questões de sermos determinados pelo meio, de herdarmos geneticamente, em oposição as possibilidade de uma construção histórica e cultural. Estas dimensões refletem também a questão do reflexo da competição, ou até mesmo, do mundo do adulto aplicado à criança.

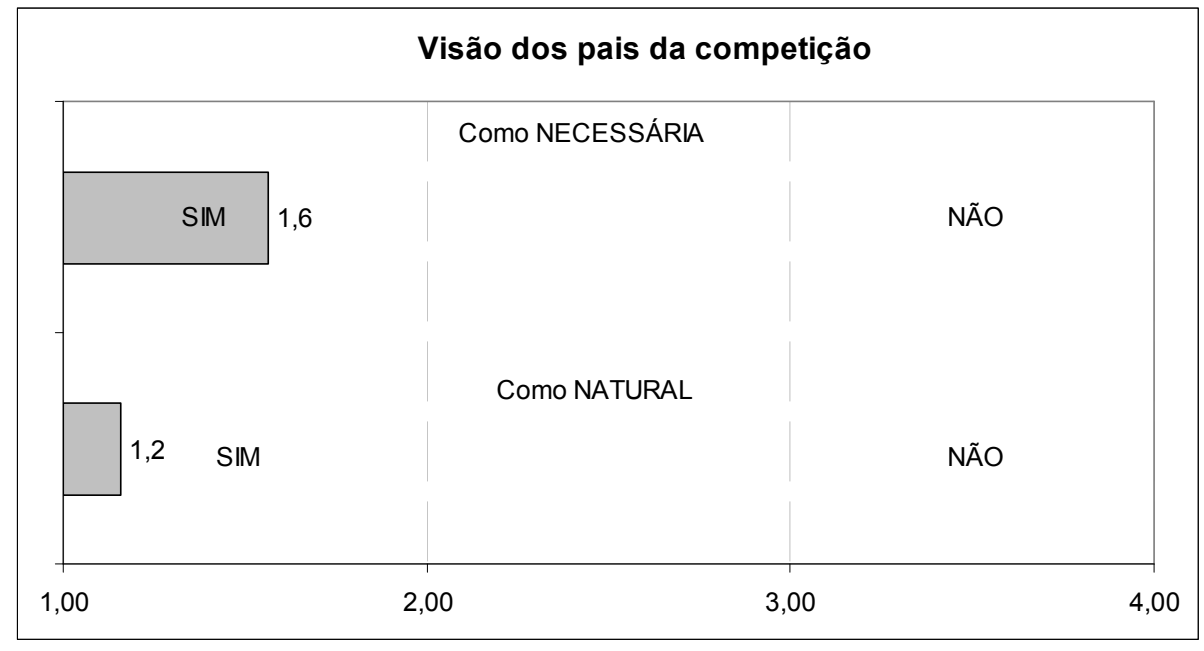

Gráfico 4 - Competição 
O gráfico 4 sintetiza a visão dos pais sobre a competição, relembrando que essas afirmações foram feitas inicialmente por pais e posteriormente foram re-testadas em um número maior de pais na forma de asserções. A visão dos pais do sexo masculino não difere significativamente das mulheres $(\mathrm{p}=0,19)$. Importante salientar que na asserção "As competições de criança selecionam os futuros atletas de ponta" nenhum pai discordou completamente e somente um ficou inclinado a discordar, ou seja, $97 \%$ dos pais concordaram que durante uma competição seus filhos estão sendo selecionados, concordando com a idéia de competição como "vitrine" de exposição dos filhos.

\section{COMO OS PAIS VÊEM O JUDÔ NA INFÂNCIA}

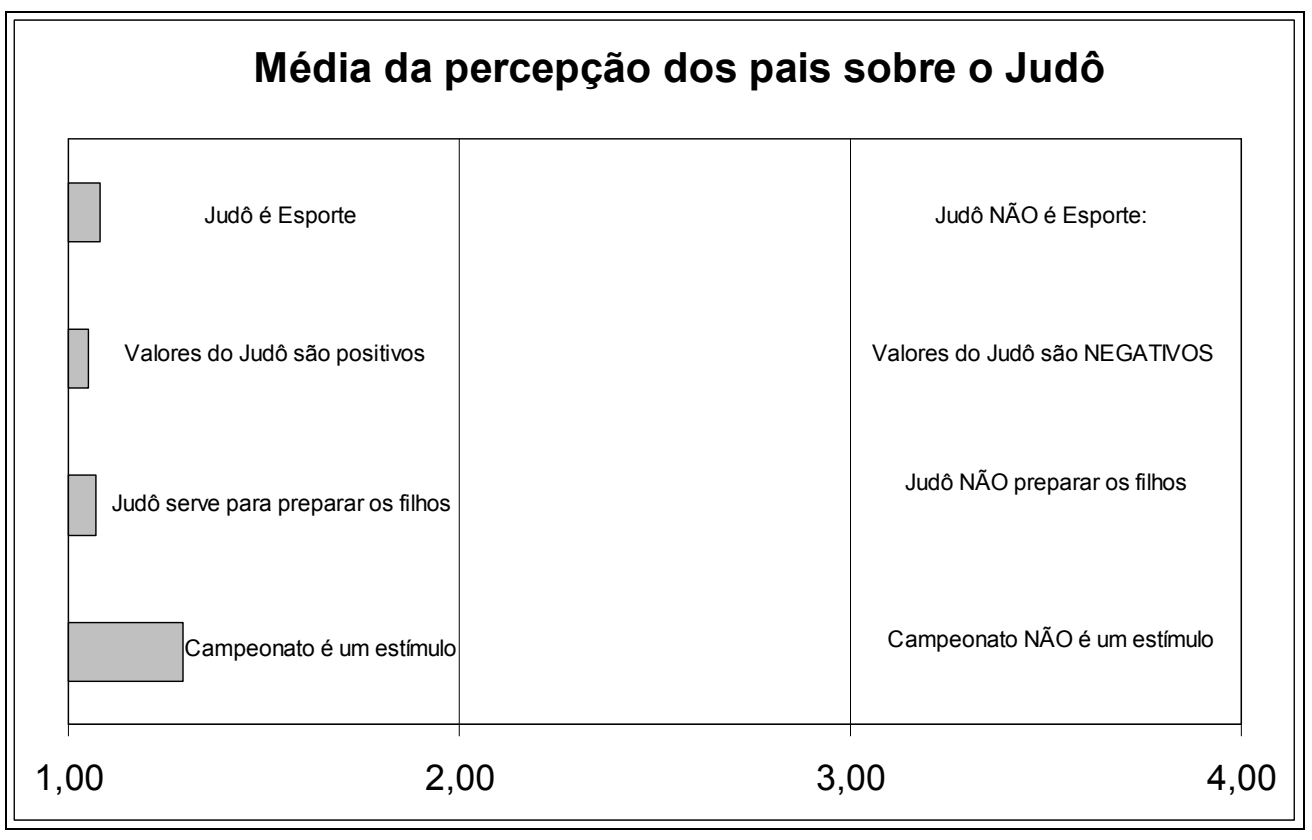

Gráfico 5 - Judô na Visão dos Pais

Procuramos nestas dimensões avaliar algumas relações que apareceram nos discursos coletados através dos instrumentos qualitativos. Nelas aparecem relações claras entre a competição e o Judô, ou seja, os resultados ficam nas zonas conclusivas.

Interessante notar que o Judô é visto como tendo valores positivos, os mesmo tempo que é visto como esporte e meio de preparação para a vida futura. Neste sentido o campeonato, que é visto como um estímulo nesta fase pelos pais, parece ter uma estrita relação com a visão que os pais tem do Judô.

Neste sentido Judô, competição de Judô e Esporte passa a atuar quase como sinônimos do discurso dos pais que vêem esses elementos como tendo valores positivos para seus filhos. 
Porém algumas contradições se estabelecem, particularmente podendo ser notadas no gráfico 6:

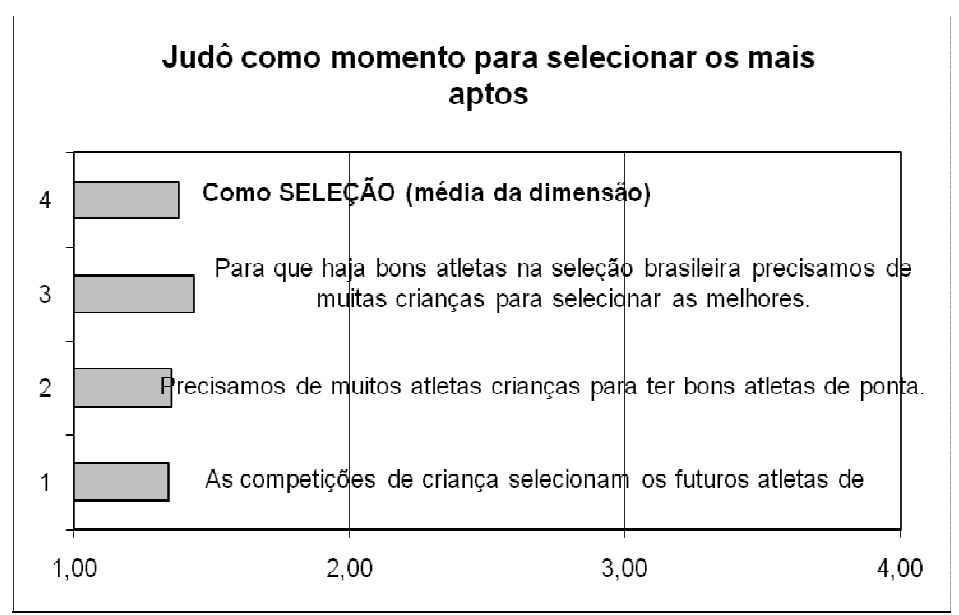

Gráfico 5 - Judô como meio de seleção.

Nesta dimensão percebemos claramente que os pais também concordam que o Judô é um momento de seleção $(1,38)$. Cabe discutir assim que é meio e quem é fim. O Judô seria um meio educacional ou até mesmo um fim recreativo que pudesse contemplar propostas coerentes com o momento vivido com as crianças e com suas necessidades presentes e futuras. Ao mesmo tempo em que se aceita que o Judô competitivo pode trazer valores, aceita-se também que as crianças devem ou possam ser selecionadas neste ambiente.

Tentamos avaliar se os pais acreditavam que era necessário começar cedo para se destacar no Judô, porém não tivemos uma média conclusiva $(2,24)$. Porém 25 pais ou $(81 \%)$ concordaram que necessário se começar cedo para alcançar a seleção brasileira. Além disso, nenhum pai discordou completamente da asserção "As crianças precisam competir" e somente 13\% ou quatro pais ficaram inclinados a discordar (sendo que 3 eram mulheres), enquanto que a grande maioria (58\%) concordaram plenamente com esta asserção. 


\section{COMO OS PAIS VÊEM OS OUTROS PAIS}

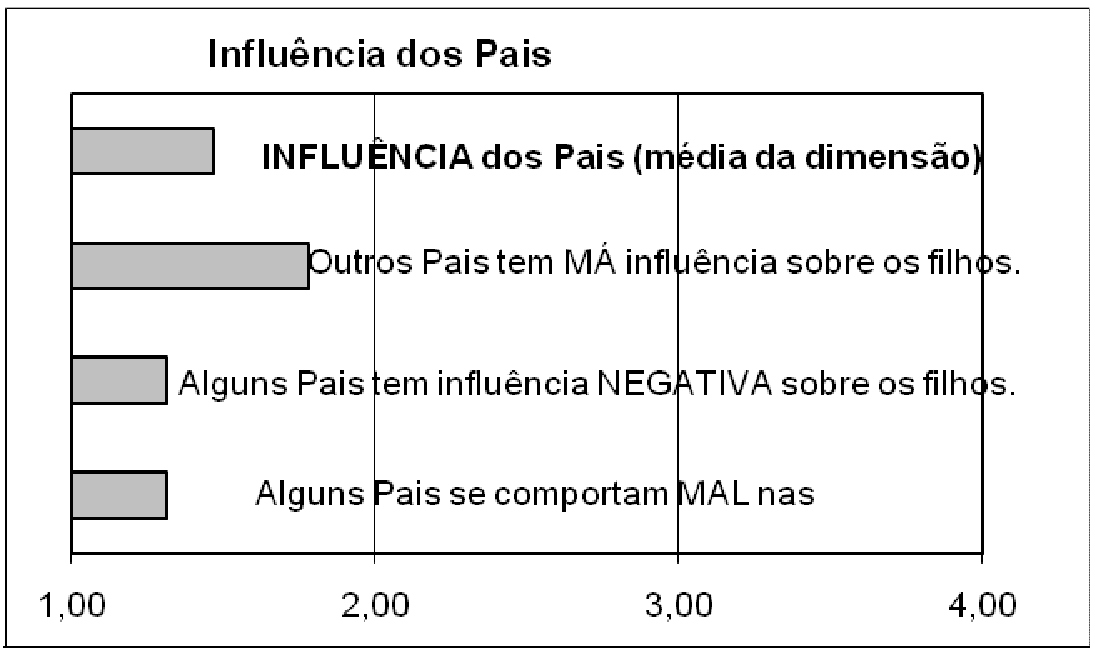

Gráfico 6 - Influência dos pais.

As asserções que procuram avalia a influência dos pais sobre os filhos na competição feitas pelos próprios pais ficaram todas na zona conclusiva, os pais veêm a influência dos outros pais como negativa sobre os filhos na competição.

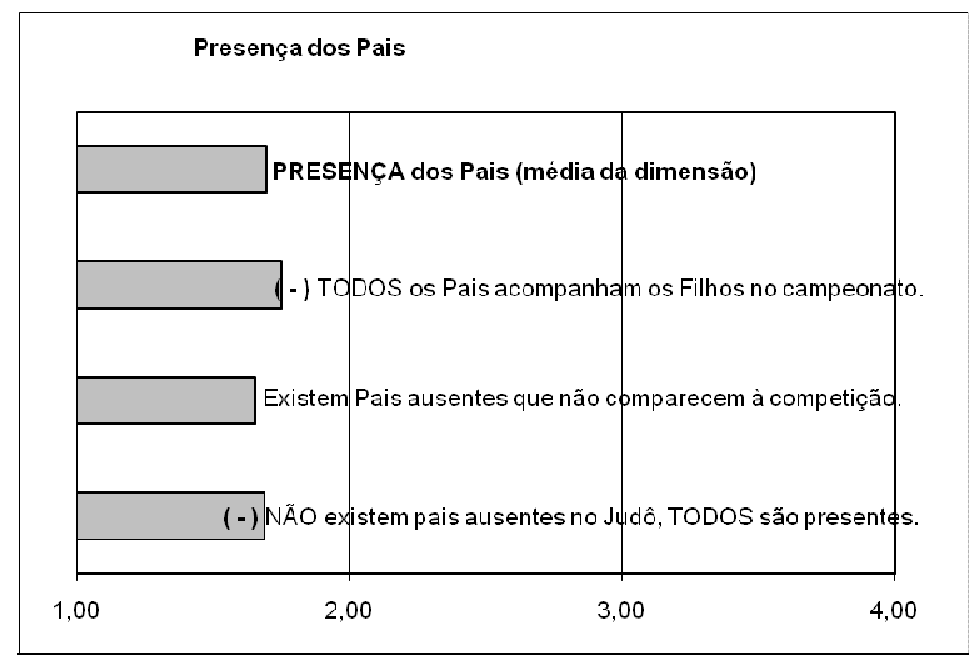

\section{Gráfico 7 - Presença dos pais.}

Questionados sobre a presença dos pais nos eventos os pais afirmam que os outros pais não comparecem, mais uma vez todas as asserções ficam na zona conclusiva, consequentimente a média da dimensão também. 


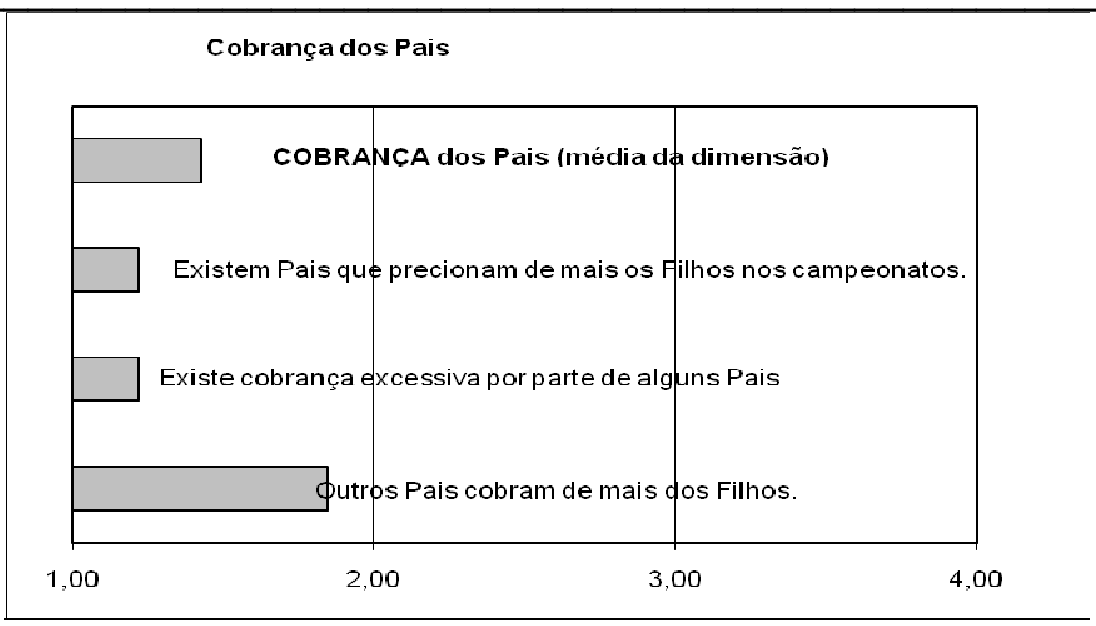

Gráfico 8 - Cobrança dos pais.

Ao avaliar a cobrança dos outros pais na competição também ficam todas as asserções na zona conclusiva, aceitando assim que os pais exercem cobrança sobre seus filhos nos eventos.

Procuramos nestas dimensões avaliar algumas relações que apareceram nos discursos coletados através dos instrumentos qualitativos. Nelas aparecem relações claras entre a competição e o Judô.

Pela média das três dimensões $(1,53)$ podemos afirmar que os pais claramente avaliam negativamente a relação de alguns pais com seus filhos. $81 \%$ dos pais concordaram plenamente que outros pais pressionam demais os filhos durante os campeonatos, os demais ficaram inclinados a concordar, sendo que ninguém discordou. 


\section{CONSIDERAÇÕES FINAIS}

Os pais exercem papel fundamental no cenário da competição dos mais jovens. Sua influência se dá na relação com os filhos, professores e dirigentes. Mais do que isso eles tem papel decisivo na escolha das práticas dos filhos e em sua permanência.

Embora muito se discuta sobre a postura do estado, das federações, das ligas, etc. os pais são os "personagens" que essencialmente tornam a participação dos filhos nestas práticas sociais possíveis.

Dessa maneira a visão de que a competição é simplesmente algo natural e necessário, somado à imagem de que o Judô é um esporte com valores positivos para os seus filhos contribui para que esse cenário se constitua da maneira que ele é, existe assim o que Bourdieu (1983) chamaria permissão tácita para que o ambiente se constitua, permitindo certa violência simbólica com consentimento daqueles que a sofrem ao aceitar que as crianças sirvam de instrumento de seleção dos mais aptos competitivamente.

Constitui-se assim certa contradição, ao mesmo tempo que o Judô, em particular a competição, é visto como sendo algo positivo para os alunos, aceita-se também que está tenha a função de selecionar e excluir, mesmo em idades bastante jovens como as primeiras categorias com 6 ou 7 anos. No processo de construção dos questionários fechados os discursos também não indicam qualquer discordância quanto à esse quadro.

Dessa maneira se partirmos do pressuposto de que a competição possa ter um valor educativo para além da seleção de atletas de elite se estabelece certa contradição. Entendendo que esse ambiente possa ser potencialmente educativo alguns princípios de inclusão precisam ser estabelecidos. Tais como os sugeridos por Cazetto e Montagner (2009).

Nesta perspectiva a competição é vista como um construto social, altamente dependente da construção simbólica que os pais têm sobre seus elementos. Os pais e os dirigente são, muitas vezes, alvos de críticas, porém é necessário ressaltar que existe um profissional com especial função neste ambiente: o professor. A ação profissional do professor deve mediar e promover possibilidade de um melhor aproveitamento da competição, possibilitando que esse fenômeno da cultura possa ser aproveitado com propósitos educativos. Rompendo com uma lógica determinista a fim de construir uma lógica educativa mais adequada às perspectivas de cada sociedade. 
Ainda é necessário ressaltar que o Estado tem especial papel neste ambiente que hoje é, em muito, construído quase que ao acaso. $\mathrm{O}$ esporte deixa assim de cumprir uma especial vocação educativa junto à sociedade.

\section{REFERÊNCIAS}

BOURDIEU, P. Questões de Sociologia. Rio de Janeiro: Marco Zero, 1983.

BRASIL. Ministério da Saúde. Sistema de Vigilância Alimentar e Nutricional - SISVAN. Orientações básicas para a coleta, processamento, análise de dados e informação em serviços de saúde. Brasília, DF, 2004. Disponível em: <http://www.saude.gov.br/alimentacao>. Acesso em: 20 abr.. 2005.

CAZETTO, F. F. Ensaio provisório sobre alguns aspetos relevantes para o entendimento tático do Judô tendo em vista a formação global do indivíduo. 2004. 160f. Trabalho de Conclusão de Curso (Graduação)-Faculdade de Educação Física, Universidade Estadual de Campinas, Campinas, 2004.

DAMATTA, R. Universo do futebol: esporte e sociedade brasileira. Rio de Janeiro: Pinakotheke, 1982.

DE ROSE JR, D. Esporte e Atividade Física na Infância. Porto Alegre: Artmed, 2002.

DE ROSE JR, D.; TRICOLI, V. Basquetebol uma visão integrada. Barueri: Manole, 2005.

FEDERAÇÃO PAULISTA DE JUDÔ. História do Judô: noções da história. São Paulo. Disponível em: $<$ http://www.fpj.com.br/historia/historia.php?id=historia_judo01.htm>. Acesso em: 16 jan. 2005.

FORJAZ, C. L. M. Os aspectos fisiológicos do crescimento e do desenvolvimento: influência do exercício físico. In: In: ROSE JUNIOR, D. Esporte e atividade física na infância e na adolescência: Uma abordagem multidisciplinar. Porto Alegre: Artmed, 2002, p.99-108.

FREIRE, J. Educação de Corpo Inteiro: teoria e prática da Educação Física. São Paulo: Scipione, 1989.

FREIRE, J. Jogo: entre o riso e o choro. Campinas: Autores Associados, 2002.

FREIRE, P. Pedagogia da Autonomia: saberes necessário à prática educativa. 7 ed. São Paulo: Paz e Terra, 1998.

LAKATOS, E. M.; MARCONI, M. A. Fundamentos de Metodologia Cientifica. 3. ed. São Paulo: Atlas, 1995.

LAPA, C. A. S. Competição Infantil, jan., 2002. Disponível em:

$<$ http://www.judobrasil.com.br/2002/lapa1.htm>. Acesso em: 12 mar. 2004.

LIKERT, R. The Method of Constructing an Attitude Scale. New York. Wiley, 1967.

Conexões: revista da Faculdade de Educação Física da UNICAMP, Campinas, v. 8, n. 1, p. 164-181, jan./abr. 2010. 
LOLLO, P. C. B.; CAZETTO, F. F.; MONTAGNER, P. C. Aspectos Nutricionais da Competição de Judô em Crianças e Adolescentes. In: Revista Digital EFDeportes. Buenos Aires, v. 10, n. 74, jul. 2004. Disponível em <http:// www.efdeportes.com/efd74/judo.htm>. Acesso em: 23 nov. 2004.

Macedo, L. Apresentação. In: FREIRE, J. Jogo: entre o riso e o choro. Campinas: Autores Associados, 2002.

MALINA, R. M.; BOUCHARD, C. Atividade Física do atleta jovem: do crescimento à maturação. São Paulo: Roca, 2002.

MATSUDO, V. Lesões e alterações osteomusculares na criança e no adolescente atleta.

MUCCHIELLI R. O questionário na pesquisa psicossocial. 2. ed. São Paulo: M. Fontes, 1979. 176p.

PAES, R. R. Aprendizagem da competição precoce: o caso do Basquetebol. Campinas: Ed. da Unicamp, 1992.

PAES, R. R.. Educação Física Escolar: o esporte como conteúdo pedagógico do ensino fundamental. Canoas: Ulbra, 2001.

PAES, R. R; BALBINO, H. F. Processo de ensino-aprendizagem do basquetebol: perspectivas pedagógicas. In: DE ROSE JUNIOR, D.; TRICOLI, V. Basquetebol uma visão integrada. Barueri: Manole, 2005.

PRONI, M. W. Esporte: história e sociedade. Campinas: Autores Associados, 2002.

RITZ, M. R. . C. Qualidade de Vida no trabalho: construindo, medindo e validando uma pesquisa. 2000. 96f. Dissertação (Mestrado em Qualidade)-Instituto de Matemática, Estatística e Computação Cientifica, Universidade Estadual de Campinas, Campinas, 2000.

SAMULSKI, D. M. Psicologia do Esporte: manual para educação física, psicologia e fisioterapia. Barueri: Manole, 2002.

SIMÕES, A.C. ; BÖHME, M. T. S.; LUCATO, S. Rev. paul. Educ. Fís., São Paulo, 13(1): 34-45, jan./jun. 1999.

SOARES, C. L. Educação Física: Conhecimento e Especificidade. In: Revista Paulista de Educação

Física. São Paulo, supl.2, p. 6-12, 1996.

SOARES, C. L.; Et al. Metodologia do ensino de Educação Física. São Paulo: Cortez, 1992.

TANI, G. et al. Educação Física Escolar: fundamentos de uma abordagem desenvolvimentista. São Paulo: Ed. da Universidade, 1988.

TZU, S. A Arte da Guerra. Rio de Janeiro: Record, 1983.

UNIVERSIDADE FEDERAL DO RIO GRANDE DO SUL. Versão em português dos instrumentos de avaliação de qualidade de vida (WHOQOL). 1998. Rio Grande do Sul. Disponível em: 
$<$ http://www.ufrgs.br/psiq/whoqol1.html>. Acesso em 15 nov. 2004.

VIRGÍlLIO, S. A arte do Judô. 3 ed. Porto Alegre: Rigel, 1994.

WINBERG, R. S.; GOULD, D. Fundamentos da Psicologia do Esporte e do Exercício. Porto Alegre: Armed, 2001. 


\section{Prof. Fabiano Filier Cazetto}

Faculdade de Educação Física-UNICAMP

E-Mail: fabianocazetto@yahoo.com.br

\section{Prof. Pablo Christiano Lollo}

Faculdade de Engenharia de Alimentos -UNICAMP

E-Mail:pablo@fea.unicamp.br

\section{Prof. Dr. Roberto Rodrigues Paes}

Professor Livre Docente em Educação Física (FEF-Unicamp)

Doutor em Metodologia do Ensino (FEF-Unicamp)

Mestre em Filosofia da Educação (Unimep)

E-Mail: robertopaes@fef.unicamp.br

\section{José Vitor Vieira Salgado}

Faculdade de Educação Física-UNICAMP

E-Mail: rotivez@yahoo.com.br

\section{Referência do artigo}

\section{ABNT}

CAZETTO, F. F.; et al., Judô e esporte dos mais jovens: os pais no cenário competitivo, Conexões, v. 8 , n. 1, p. 164-181, 2010

\section{APA}

Cazetto, F. F., Lollo, P. C., Paes, R. R., \& Salgado, J. V. V. (2010). Judô e esporte dos mais jovens: os pais no cenário competitivo, Conexões, 8(1), 164-181.

\section{VANCOUVER}

Cazetto, FF, Lollo, PC, Paes, RR. \& Salgado, JVV. (2010). Judô e esporte dos mais jovens: os pais no cenário competitivo. Conexões; 8(1): 164-181.

Artigo recebido em 24/11/2009

Aceito para publicação em 06/02/2010 